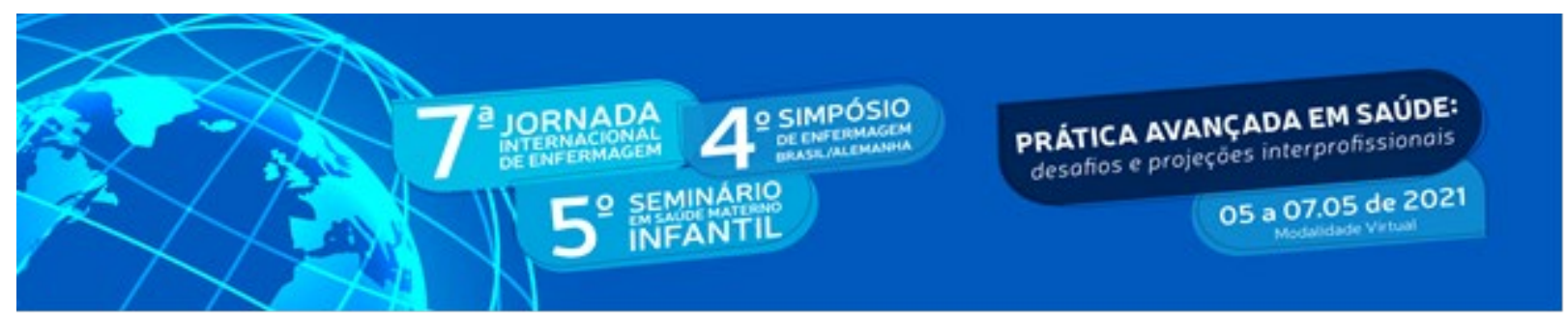

DOI: http://doi.org/10.48195/jie2021-096

\title{
SITUAÇÃO VACINAL DA ANTIPÓLIO DE CRIANÇAS DE 2 MESES A MENORES DE 10 ANOS
}

\section{Clara Costa Fontes ${ }^{2}$; Francisca Georgina Macedo de Sousa ${ }^{3}$; Gabrielle Pontes Santos ${ }^{4}$; Jéssica Nathália de Melo Sousa ${ }^{5}$; Nathália da Silva Licar ${ }^{6}$; Vanessa Dias da Silva ${ }^{7}$}

\begin{abstract}
RESUMO
Objetivo: Categorizar situação vacinal contra poliomielete de crianças de 2 meses a menores de 10 anos. Metodologia: Estudo documental, descritivo com abordagem quantitativa. Foi analisado esquema de antipólio registrado na Caderneta de Saúde da Criança pelos profissionais da Atenção Primária em Saúde de São Luís-MA. Resultado: Das 1786 CSC, 1587 (88,85\%) iniciaram esquema aos 2 meses e $1376(77,04 \%)$ encontravam-se com esquema completo e $410(22,95 \%)$ incompleto. O intervalo, tanto 1 a -2 a dose quanto 2 a -3 a dose VIP, foi segundo recomendado, com, respectivamente, $77,04 \%$ e 67,69\%, já 3a dose VIP - 1 reforço VOP, o maior achado foi "Atrasou: $\geq 1$ mês além do recomendado" com 31,58\% das CSC. Conclusão: O Brasil corre risco de importação do poliovírus e, consequentemente, surtos epidêmicos, caso ocorra a diminuição da cobertura vacinal, haverá aumento de indivíduos suscetíveis. Daí a necessidade de maior rastreamento de crianças com atraso vacinal para atualização do esquema de antipólio.
\end{abstract}

Palavras-chave: Calendário Básico de Vacinação da Criança; Doença Prevenível por Vacina; Erradicação de Doença; Poliomielite.

\section{ABSTRACT}

Objective: To categorize vaccination status against polio in children aged 2 months to less than 10 years. Methodology: Documentary, descriptive study with a quantitative approach. An anti-polio scheme registered in the Child Health Handbook by professionals in Primary Health Care in São LuísMA was analyzed. Result: Of the 1786 CSC, 1587 (88.85\%) started the scheme at 2 months and 1376 (77.04\%) were with a complete scheme and 410 (22.95\%) incomplete. The interval, both 1st-2nd dose and 2nd-3rd dose VIP, was second recommended, with, respectively, $77.04 \%$ and $67.69 \%$, whereas 3rd VIP dose - 1st VOP booster, the biggest finding was "Delayed: $\geq 1$ month beyond recommended "with $31.58 \%$ of CSC. Conclusion: Brazil is at risk of importing poliovirus and, consequently, epidemic outbreaks, if there is a decrease in vaccination coverage, there will be an increase in susceptible individuals. Hence the need for greater screening of children with vaccination delay in order to update the anti-polio scheme.

Key Words: Basic Child's Vaccination schedule; Vaccine-Preventable Disease; Disease Eradication; Poliomyelitis.

\footnotetext{
${ }^{1}$ Grupo de Ensino e Pesquisa na Saúde da Família, Criança e Adolescente - GEPSFCA

${ }^{2}$ Estudante do Curso de Enfermagem. UFMA. Email: clarafontes17@gmail.com

${ }^{3}$ Orientadora. Pós-doutora em Enfermagem. Docente UFMA. Email: georginamacedo17@gmail.com

${ }^{4}$ Estudante do Curso de Enfermagem. UFMA. Email: gabriellepontessp@gmail.com

${ }^{5}$ Enfermeira Residente em Saúde da Criança. HUUFMA. Email: jessica-nathy@hotmail.com

${ }^{6}$ Estudante do Curso de Enfermagem. CEST. Email: nathalya.licar.nl@gmail.com

${ }^{7}$ Estudante do Curso de Enfermagem. UFMA. Email: vanessad25978@gmail.com
} 


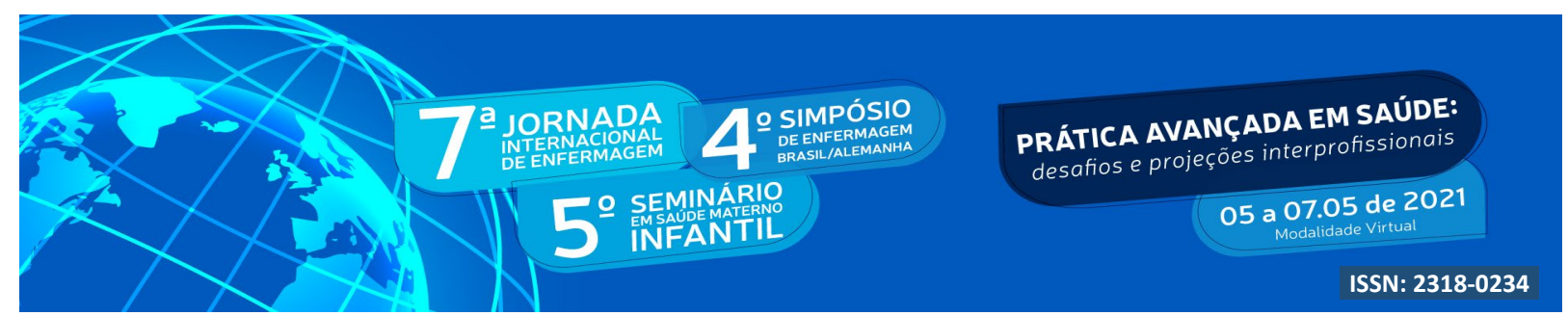

\section{INTRODUÇÃO}

\section{A poliomielite no Brasil: dos primeiros relatos a erradicação}

No Brasil, o marco inicial da poliomielite ocorreu em 1911, com os primeiros registros dos médicos Luiz Hoppe, que atuava na Santa Casa de Misericórdia de São Paulo, e de Oswaldo Oliveira, do Hospital Misericórdia no Rio de Janeiro (DURANTE e DAL POZ, 2014). No mesmo ano, o Dr. Fernandes Figueira realiza a primeira documentação de um surto da patologia no Rio de Janeiro e em 1930, quando surtos começam a se espalhar pelas áreas urbanas, a poliomielite passa a ser reconhecida como um problema de saúde pública no país (NETO TAVARES, 2015; SILVA e CÂMARA, 2011).

Segundo Neto Tavares (2015), nessa época ainda não havia nenhuma forma oficial e comprovada de controle da doença. Somente em 12 de abril de 1955 que esse cenário é revertido, após a vacina Salk (VIP) ser aprovada como segura e efetiva, num nível de 70\%, através de um experimento que envolveu quase dois milhões de crianças de vários locais dos Estados Unidos, do Canadá e Finlândia. Ainda segundo o autor, no mesmo ano, no Brasil, secretarias municipais e estaduais de saúde, principalmente nos Estados de São Paulo e no Rio de Janeiro, realizaram a promoção de pequenas campanhas de vacinação com a VIP, iniciando o método de prevenção contra a doença no país. Nos anos subsequentes, os órgãos competentes tomaram algumas medidas e assumiram responsabilidades com intuito de controlar as manifestações da doença no território brasileiro, como, por exemplo, o Plano Nacional de Controle da Poliomielite (PNCP) de 1971 (SILVA e CÂMARA, 2011).

Em 1974, surge o Programa Nacional de Imunização (PNI) e o PNCP é incorporado ao mesmo, que passa a estabelecer a vacinação de rotina com a vacina Sabin (VOP) em nível nacional, e em 1989 são registrados os últimos casos da doença no Brasil após um período de realização de grandes campanhas vacinais e vigilância epidemiológica (SILVA e CÂMARA, 2011). Com todas as medidas adotadas mundialmente, em 1991, é registrado no Peru o último caso das Américas, o que resultou na certificação dos países da américa pela Organização Mundial de Saúde/Organização Panamericana de Saúde o "Certificado de Erradicação da 


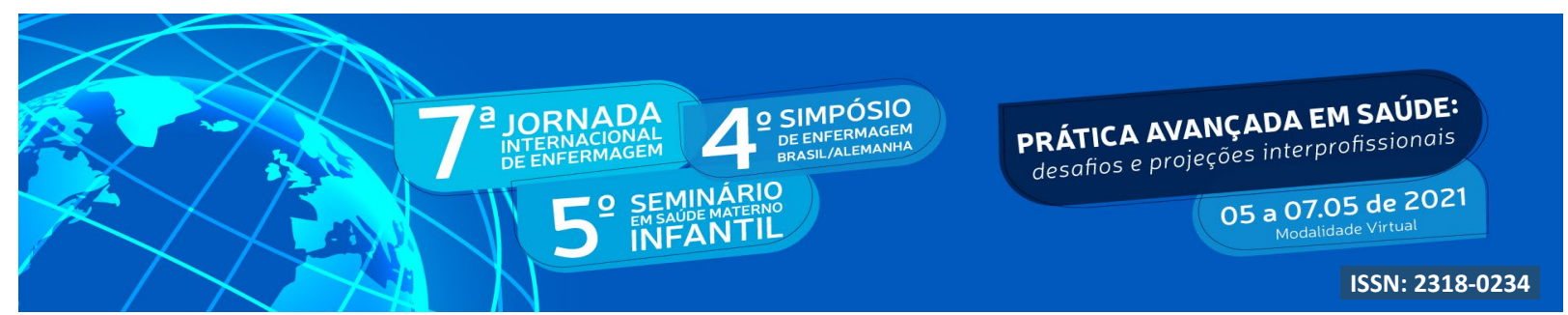

Transmissão Autóctone do Poliovírus Selvagem nas Américas" (SILVA e CÂMARA, 2011; NETO TAVARES, 2015).

Desde então, o Brasil continua reafirmando seu compromisso, uma das provas é o atual esquema vacinal para a antipólio, disponibilizado pelo Calendário Básico de Vacinação da Criança, que é composto por três doses com a vacina VIP - aos dois, quatro e seis meses de vida -, e dois reforços com a VOP - aos 15 meses e a última aos 4 anos. Sendo que, o Ministério da Saúde (MS) assegura o direito ao acesso a vacina até os 4 anos, 11 meses e 29 dias (BRASIL, 2020).

Entretanto, em 2012, a doença voltou a se tornar emergência global, após o registro de surtos em países que, até então, estavam livres da patologia (DURANTE e DAL POZ, 2014). Em meio a este cenário, evidencia-se o papel do Brasil em garantir que a doença não se torne reemergente, através da vacinação como método mais eficaz de prevenção a doenças infectocontagiosas. Diante deste novo cenário questiona-se: Qual a situação vacinal da vacina antipólio de crianças atendidas nas Undiades Básicas de Saúde de São Luís?

\section{OBJETIVOS}

Geral: Categorizar situação vacinal do imunobiológico contra poliomielite a partir dos registros da Caderneta de Saúde da Criança em Saúde de crianças de 2 meses a menores de 10 anos de idade

\section{Específicos:}

- Identificar, segundo faixa etária, o número de doses recebidas da vacina antipólio;

- Determinar o início do esquema com a vacina antipólio;

- Descrever o intervalo utilizado entre as doses da vacina antipólio.

\section{METODOLOGIA}

Pesquisa descritiva, transversal, com abordagem quantitativa e documental, onde foram avaliados os registros realizados na Caderneta de Saúde da Criança (CSC) pelos 


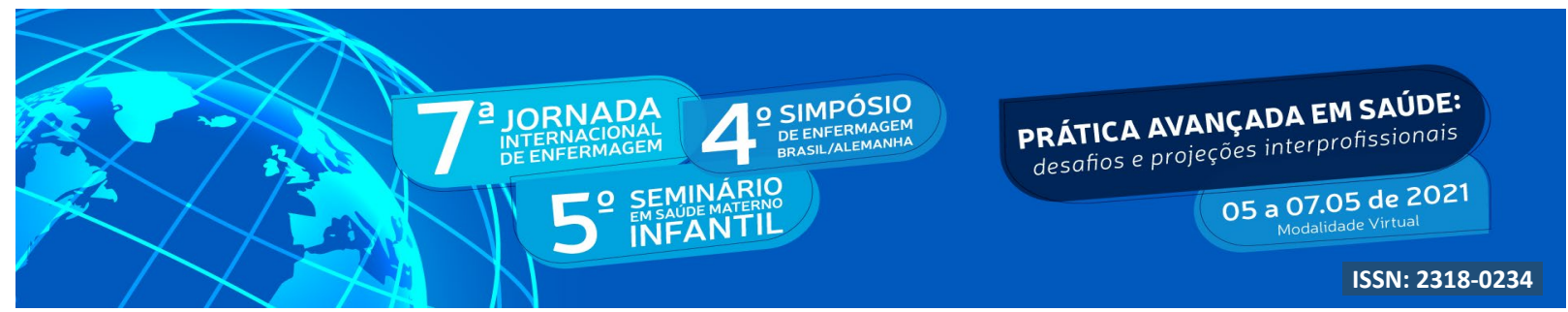

profissionais da Atenção Primária em Saúde. Para a análise da situação vacinal das crianças, considerou-se as edições $7 \underline{a}$ e $8^{a}$ da CSC.

Enfatiza-se que se trata de um recorte da Pesquisa "Caderneta de Saúde da Criança e o manejo profissional das ações de saúde infantil”, cujo objetivo é identificar como as ações de saúde da criança são registradas na CSC. Esta pesquisa encontra-se vinculada ao Departamento de Enfermagem da Universidade Federal do Maranhão sob a coordenação do Grupo de Pesquisa na Saúde da Família, Criança e Adolescente - GEPSFCA e foi submetida a Plataforma Brasil com o CAAE $n^{\circ}$ 17772819.1.0000.5087, no qual recebeu parecer de aprovação.

A coleta de dados foi realizada nas salas de vacinação das Unidades Básicas de Saúde (UBS) do município de São Luís, capital do Estado do Maranhão. Onde, utilizou-se um único critério para a seleção das UBS, que foi incluir aquelas com 1000 ou mais atendimentos ambulatoriais por ano de crianças menores de 10 anos. Sendo assim, das 57 UBS do município, 31 participaram da pesquisa.

A meta da pesquisa maior é de $2.305 \mathrm{CSC}$, entretanto, devido a dificuldades que impossibilitaram o término da coleta, como, a pandemia da COVID-19, a reforma de algumas unidades de saúde e a diminuição do fluxo de crianças devido a pandemia, foi utilizado o recorte da pesquisa de 1889 CSC. Para este estudo considerou-se apenas as crianças a partir de 2 meses, já que é a partir desta idade que estão aptas a receber a primeira dose da vacina antipólio. Sendo assim, como 103 cadernetas apresentavam idade $<2$ meses, foram analisados os registros de 1786 CSC no período de maio de 2019 a dezembro de 2020.

Para a análise da situação vacinal das CSC, foi utilizado duas variáveis: "Completo", para CSC com idade $\geq 6$ meses e com registro das três doses preconizados; e "Incompleto", para aquelas que constavam idade $<6$ meses, ou seja, não aptas a completar o esquema, e $\geq 6$ meses, aptas a completar o esquema, porém com ausência de uma ou mais doses da vacina.

Enquanto que, para averiguação do início da vacinação, foi utilizado as classificações "Antes de 2 meses", para as CSC que apresentaram registro da vacina antes da idade recomendada; "Com 2 meses de idade", para aqueles que apresentaram o registro entre $\geq 2$ meses a $<3$ meses; "Com $\geq 3$ meses de idade", para as que possuíam entre $\geq 3$ meses a $<6$ meses; "Com $\geq 6$ meses de idade", para as que se encontravam entre o intervalo de $\geq 6$ meses 




a $<12$ meses; "Com $\geq 12$ meses de idade", para as amostras com $\geq 12$ meses a 1 ano, 5 meses e 8 dias, que foi a maior idade identificada no cálculo da data de administração da 1a dose VIP; "Não iniciou o esquema vacinal", para as que não possuíam nenhum registro; "Não há como avaliar: sem registro da data de administração da vacina”, para as CSC que possuíam nome da unidade, do vacinador e/ou lote, porém não apresentavam menção a data da aplicação da dose.

No que concerne ao intervalo de tempo entre as doses, o Ministério da Saúde (BRASIL, 2020) preconiza para a vacina antipólio o período de tempo mínimo (30 dias) e o recomendado (2 meses), devendo ser priorizado o seguimento do que é recomendado. Sendo que, nunca se reinicia o esquema, caso ocorra atraso entre a administração das doses, o indivíduo sempre prosseguirá a partir da dose que se deu a descontinuação. Mediante isto, o MS não estabelece um intervalo máximo, podendo o indivíduo ter acesso ao esquema do imunobiológico contra a pólio enquanto for menor de 5 anos (BRASIL, 2020). Entretanto, entende-se que, o esquema vacinal deve ser completo o mais rapidamente possível, pois enquanto o esquema não for finalizado, a criança não possui imunidade totalmente eficiente contra a doença, o que a torna parcialmente suscetível a contrai-la no espaço de tempo que consta o atraso além do tempo recomendado.

Sendo assim, foram elaboradas 8 variáveis para análise do intervalo entre as doses, sendo elas: "Segundo intervalo recomendado de 2 meses", para as CSC que apresentavam de 2 meses a $<3$ meses entre os registros; "Segundo intervalo mínimo de 30 dias", para as que apresentavam o intervalo entre 30 dias a $<2$ meses; "Antes do intervalo mínimo de 30 dias", para os intervalos constatados como tal; "Não constava registro", para as que não apresentavam registro de uma ou ambas as doses; "Sem registro da data de administração" para as identificadas com ausência da data de administração de uma ou ambas as doses; e para averiguação do tempo de atraso entre as doses, foi utilizado as seguintes variáveis: Atrasou: $\geq$ 1 mês além do recomendado; Atrasou: $\geq 4$ meses além do recomendado; e Atrasou: $\geq 1$ ano além do recomendado.

Até 2015, a vacina utilizada como 3ạ dose no Calendário Básico de Vacinação da Criança era a VOP. Entretanto, devido a mudanças na situação epidemiológica da poliomielite no Brasil, decorrente da erradicação do sorotipo 2, no início de 2016, a vacina contra a pólio 


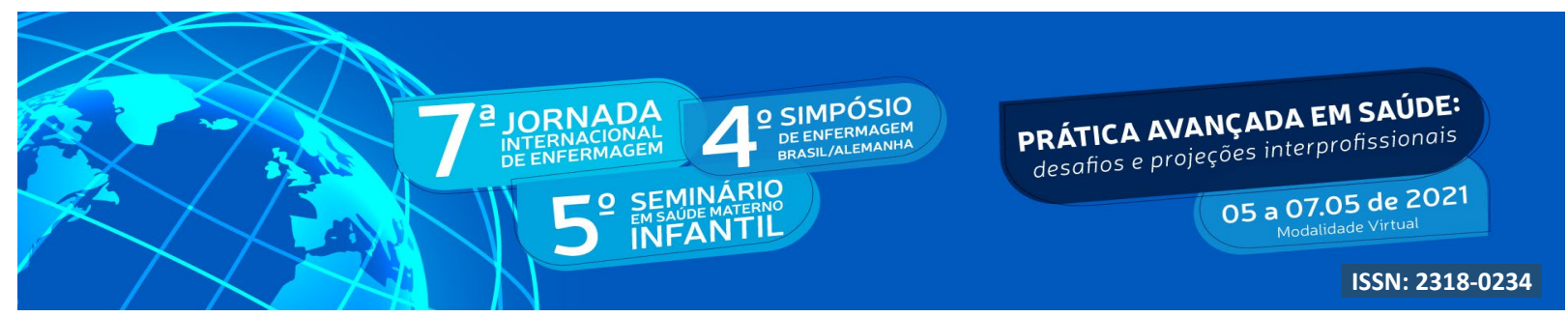

para a terceira dose passou a ser VIP (MATO GROSSO, 2016). Sendo assim, na avaliação do intervalo entre a 3a dose VIP - 1ำ reforço VOP, além, das demais variáveis, foi identificado a variável "Recebeu o $1^{\circ}$ reforço, sem ter recebido a $3^{\text {a }}$ dose", que foi utilizado em CSC com o ano de nascimento $\geq 2016$, com registro do $1^{\circ}$ reforço VOP, porém com ausência da $3^{\mathrm{a}}$ dose VIP.

Para esta pesquisa, o segundo reforço da VOP não foi incluída na análise de dados, já que, na 7ạ e 8a edição da CSC constava em "outras vacinas". Portanto, sua inclusão na pesquisa poderia levar a inconcistência dos dados.

\section{RESULTADOS E DISCUSSÃO}

Tabela 1. Esquema vacinal de antipólio em crianças de 2 meses a menores de 10 anos segundo registros da CSC - São Luís/MA, 2019/2020.

\begin{tabular}{|c|c|c|}
\hline Situação vacinal & $\mathbf{N}$ & $\mathbf{\%}$ \\
\hline Completo & 1376 & $77,04 \%$ \\
\hline Incompleto & 410 & $22,95 \%$ \\
\hline TOTAL & $\mathbf{1 7 8 6}$ & $\mathbf{1 0 0 \%}$ \\
\hline
\end{tabular}

Fonte: dados da pesquisa

Das 1786 CSC, 77,04\% apresentavam idade apta e continham o registro do número de doses compatível com o que é preconizado para completude do esquema vacinal. Em contrapartida, 22,95\% das CSC revelaram esquema vacinal incompleto.

Tabela 2. Esquema vacinal de antipólio incompleto segundo registros da CSC - São Luís/MA,

\begin{tabular}{|c|c|c|}
\hline \multicolumn{2}{|c|}{$2019 / 2020}$. \\
Esquema incompleto & $\mathbf{N}$ & $\mathbf{\%}$ \\
\hline Idade não recomendada: $\geq 2$ meses a $<6$ meses & 300 & $73,17 \%$ \\
\hline Não recebeu uma ou mais doses: $\geq 6$ meses & 110 & $26,82 \%$ \\
\hline TOTAL & $\mathbf{4 1 0}$ & $\mathbf{1 0 0 \%}$ \\
\hline
\end{tabular}

Fonte: dados da pesquisa

Sendo que, das 410 CSC que constavam incompletude, 300 (73,17\%) não possuíam idade apta para conclusão do esquema e, apesar da vacina antipólio ser um dos imunobiológicos de maior divulgação nacional e ter alta eficácia comprovada, 110 (26,82\%) não haviam completado mesmo tendo/ já tido idade oportuna para o tê-lo. 


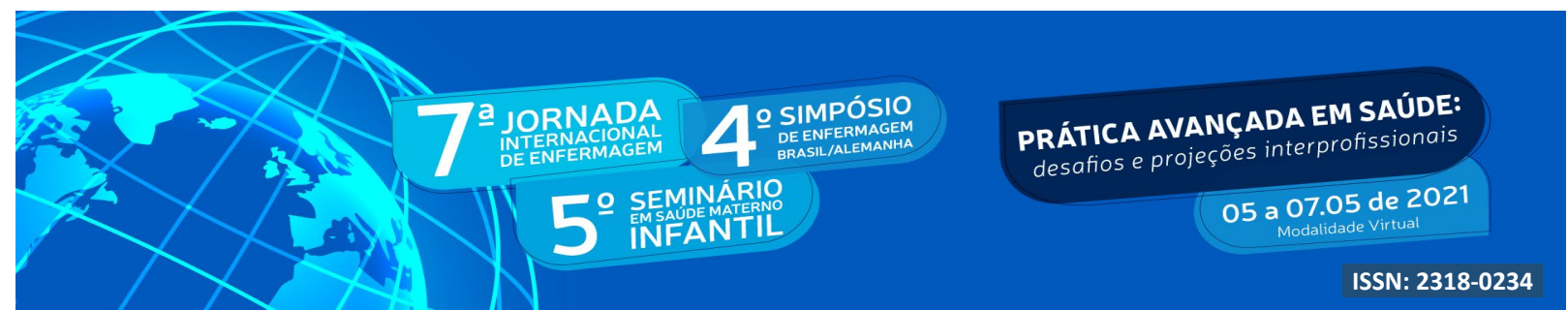

Tabela 3. Faixa etária das CSC com incompletude do esquema vacinal antipólio com $\geq 6$ meses de idade . Dados da CSC - São Luís/MA, 2019/2020.

\begin{tabular}{|c|c|c|}
\hline Faixa etária & $\mathbf{N}$ & $\mathbf{\%}$ \\
\hline$<4$ anos, 11 meses e 29 dias & 106 & $96,36 \%$ \\
\hline$>4$ anos, 11 meses e 29 dias & 4 & $3,6 \%$ \\
\hline TOTAL & $\mathbf{1 1 0}$ & $\mathbf{1 0 0 \%}$ \\
\hline
\end{tabular}

Fonte: dados da pesquisa

Das 110 CSC com incompletude e idade $\geq 6$ meses, 96,36\% ainda se encontravam em idade hábil para recebimento da vacina e 3,6\% possuía idade $>4$ anos, 11 meses e 29 dias, portanto, não mais havendo indicação de administração das doses conforme preconizado pelo Ministério da Saúde.

Tabela 4. Doses da vacina antipólio registradas na CSC de crianças de 2 meses a menores de 10 anos - São Luís/MA, 2019/2020.

\begin{tabular}{|c|c|c|c|c|c|c|}
\hline \multirow{2}{*}{ Dose } & \multicolumn{2}{|c|}{ Constava registro } & Não constava registro & \multicolumn{2}{c|}{ TOTAL } \\
\cline { 2 - 7 } & $\mathbf{N}$ & $\mathbf{\%}$ & $\mathbf{N}$ & $\mathbf{\%}$ & $\mathbf{N}$ & $\mathbf{\%}$ \\
\hline 1ㅁ dose: $\geq 2$ meses & 1760 & $98,54 \%$ & 26 & $1,45 \%$ & $\mathbf{1 7 8 6}$ & $\mathbf{1 0 0 \%}$ \\
\hline 2a dose: $\geq 4$ meses & 1551 & $96,99 \%$ & 48 & $3,00 \%$ & $\mathbf{1 5 9 9}$ & $\mathbf{1 0 0 \%}$ \\
\hline 3a dose: $\geq 6$ meses & 1377 & $92,66 \%$ & 109 & $7,33 \%$ & $\mathbf{1 4 8 6}$ & $\mathbf{1 0 0 \%}$ \\
\hline 1ㅇ Reforço: $\geq 15$ meses & 923 & $87,82 \%$ & 128 & $12,17 \%$ & $\mathbf{1 0 5 1}$ & $\mathbf{1 0 0 \%}$ \\
\hline
\end{tabular}

Fonte: dados da pesquisa

Durante o processamento dos dados foi identificado um maior percentual na variável “Constava registro", que foi averiguado desde a 1a dose $(98,54 \%)$ até o 1 o reforço $(87,82 \%)$. Porém, também foi identificado um aumento considerável na ausência de registros, que foi de $1,45 \%$ na 1 a dose para $12,17 \%$ no 10 reforço.

Tabela 5. Idade do início do esquema vacinal de antipólio segundo registros da CSC - São Luís/MA,

\begin{tabular}{|l|c|c|}
\hline \multicolumn{2}{l|}{$2019 / 2020}$. & $\mathbf{N}$ \\
\hline Início da vacinação com antipólio & $\mathbf{N}$ & $0,55 \%$ \\
\hline Antes de 2 meses & 1587 & $88,85 \%$ \\
\hline Com $\geq 2$ meses de idade & 143 & $8,00 \%$ \\
\hline Com $\geq 3$ meses de idade & 11 & $0,61 \%$ \\
\hline Com $\geq 6$ meses de idade & 3 & $0,16 \%$ \\
\hline Com $\geq 12$ meses de idade & 28 & $1,56 \%$ \\
\hline Não iniciou o esquema vacinal & 04 & $0,22 \%$ \\
\hline Não há como avaliar: sem registro da data de administração da vacina & $\mathbf{1 7 8 6}$ & $\mathbf{1 0 0 \%}$ \\
\hline TOTAL
\end{tabular}

Fonte: dados da pesquisa 


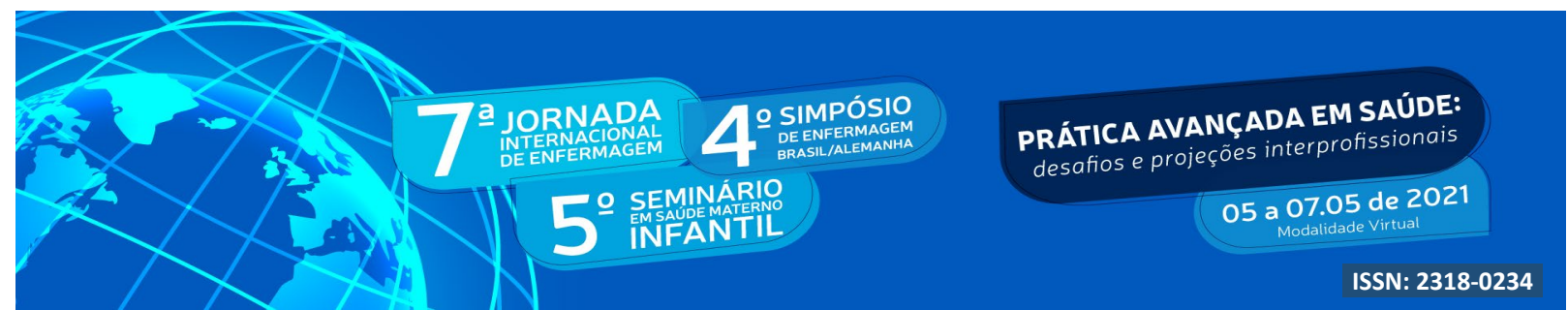

Quanto ao início da vacinação, em $88,85 \%$ das CSC, a idade utilizada foi a preconizada pelo MS. Em 0,55\% dos casos, não foi respeitado a idade mínima para administração da dose e, em $0,16 \%$ das CSC, foi identificado o início tardio de $\geq 12$ meses de idade.

Tabela 6. Intervalo entre as doses da vacina VIP segundo registros da CSC. São Luís/MA, 2019/2020

\begin{tabular}{|c|c|c|c|c|}
\hline \multirow{2}{*}{ Variavéis } & \multicolumn{2}{|c|}{ 1a-2a dose VIP } & \multicolumn{2}{|c|}{ 2a-3a dose VIP } \\
\hline & $\mathrm{N}$ & $\%$ & $\mathrm{~N}$ & $\%$ \\
\hline Segundo intervalo recomendado de 2 meses & 1232 & $77,04 \%$ & 1006 & $67,69 \%$ \\
\hline Segundo intervalo mínimo de 30 dias & 50 & $3,12 \%$ & 54 & $3,63 \%$ \\
\hline Antes do intervalo mínimo de 30 dias & 4 & $0,25 \%$ & 2 & $0,13 \%$ \\
\hline Atrasou: $\geq 1$ mês além do recomendado & 214 & $13,38 \%$ & 269 & $18,10 \%$ \\
\hline Atrasou: $\geq 4$ meses além do recomendado & 41 & $2,56 \%$ & 45 & $3,02 \%$ \\
\hline Atrasou: $\geq 1$ ano além do recomendado & 5 & $0,31 \%$ & 7 & $0,47 \%$ \\
\hline Não constava registro & 43 & $2,68 \%$ & 89 & $5,98 \%$ \\
\hline Sem registro da data de administração & 10 & $0,62 \%$ & 14 & $0,94 \%$ \\
\hline TOTAL & 1599 & $100 \%$ & 1486 & $100 \%$ \\
\hline
\end{tabular}

Fonte: dados da pesquisa

Tabela 7. Intervalo entre as doses VIP/VOP. Dados da CSC - São Luís/MA, 2019/2020

\begin{tabular}{|c|c|c|}
\hline \multirow{2}{*}{ Variáveis } & 3a dose VIP - 10 reforço VOP \\
\cline { 2 - 3 } Segundo intervalo recomendado de 2 meses & $\mathrm{N}$ & $\%$ \\
\hline Segundo intervalo mínimo de 30 dias & 324 & $30,82 \%$ \\
\hline Antes do intervalo mínimo de 30 dias & 36 & $3,42 \%$ \\
\hline Atrasou: $\geq 1$ mês além do recomendado & 33 & $3,13 \%$ \\
\hline Atrasou: $\geq 4$ meses além do recomendado & 332 & $31,58 \%$ \\
\hline Atrasou: $\geq 1$ ano além do recomendado & 150 & $14,27 \%$ \\
\hline Não constava registro & 28 & $2,66 \%$ \\
\hline Sem registro da data de administração & 123 & $11,70 \%$ \\
\hline Recebeu o 10 reforço, sem ter recebido a 3a dose & 10 & $0,95 \%$ \\
\hline TOTAL & 15 & $1,42 \%$ \\
\hline
\end{tabular}

Fonte: dados da pesquisa

$\mathrm{Na}$ avaliação do intervalo entre as doses, a maior parcela de achados foi de "Segundo intervalo recomendado de 2 meses" tanto no tempo utilizado entre a $1 \underline{a}$ e a $2 \underline{a}$ dose $(77,04 \%)$, quanto entre a 2 a e a 3 a dose $(67,69 \%)$ de VIP. Entretanto, no intervalo entre a 3 a dose VIP - 


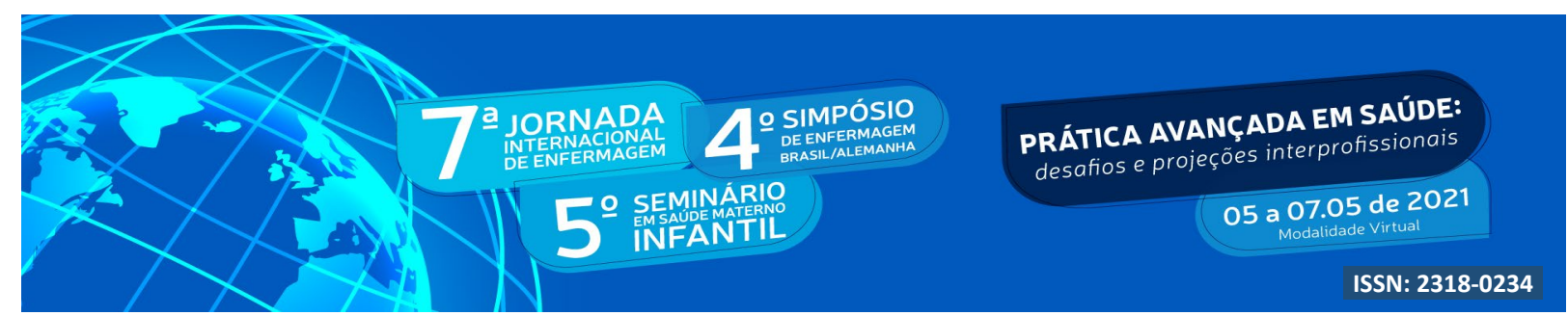

1 reforço VOP, foi constatado que esse cenário se modifica e a variável "Atrasou: $\geq 1$ mês além do recomendado" é a que apresenta maior frequência com 31,58\% das amostras. Outra inconsistência entre a 3 a dose VIP - 1 ㅇeforço VOP foi a constatação de 15 CSC (1,42\%) que possuíam o registro do $1^{\mathrm{o}}$ reforço VOP, sem ter registro da $3^{\mathrm{a}}$ dose VIP, ou seja, sem ter completado o esquema vacinal.

\section{CONCLUSÃO}

Situações como a incompletude de doses, atraso e desrespeito do intervalo preconizado entre as doses, início da vacinação antes da idade mínima recomendada, falta de registro da data de acesso ao imuniobológico e admnistração do reforço antes da finalização do esquema de doses estabelecido, foram algumas das inconsistências encontradas durante a análise dos dados. Entretanto, salvo caso o intervalo entre a 3 ㅇ dose VIP - 1 reforço VOP, a pesquisa identificou uma parcela maior de registro adequados.

Porém, situações como crianças em idade oportuna buscando atendimento na sala de vacinação e, ainda assim, saindo da UBS com esquema incompleto, podem indicar a falta de planejamento na aquisição das doses em número equivalente a demanda. Enquanto que, os atrasos além do recomendado, podem indicar reflexos das barreiras existentes no contato usúario/sistema de saúde, como o horário de funcionamento das UBS's que, geralmente, são em horário comercial, o que dificulta o acesso dos responsáveis assalariados.

Outro ponto que pode acarretar no atraso e incompletude do esquema vacinal, que foi observado pelas pesquisadoras durante a coleta dos dados, é a falta de acolhimento por parte dos profissionais aos usúarios, no que concerne a educação em saúde, já que, antes da administração da vacina, deve ocorrer orientação sobre a importância da vacinação e da conclusão do esquema básico de acordo com o que é recomendado. Entretanto, em raros casos foi observado a realização de promoção dos imunobiológicos.

Sendo assim, levando em consideração que o Brasil é um país com erradicação regional do poliovírus selvagem e que, ainda corre o risco de uma possivel importação do vírus de países endêmicos e, consequentemente, surtos epidêmicos, se evidencia a necessidade de averiguação da situação da vacina antipólio no calendário infantil de crianças de todo território brasileiro, principalmente no que concerne ao contexto fora das UBS's. 


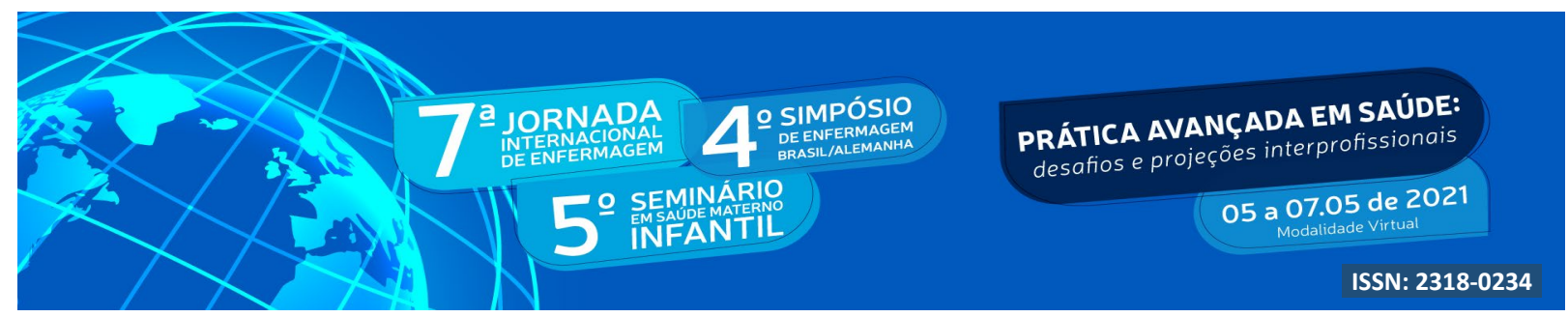

Pois, se faz necessário o rastreamento de CSC com atraso vacinal e o levantamento de erros recorrentes no processo de administração do esquema, que possam afetar no desenvolvimento de uma resposta imune satisfátoria e em contrapartida, na cobertura vacinal, já que esses dados são fundamentais para nortear a elaboração de intervenções eficientes para garantia das boas práticas.

\section{REFERÊNCIAS}

BRASIL. Ministério da Saúde. Coordenação Geral do Programa Nacional de Imunizações. Departamento de Imunização e Doenças Transmissíveis. Secretaria de Vigilância em Saúde. Instrução Normativa Referente ao Calendário Nacional de Vacinação 2020, 19 de fev. de 2020. Disponível em: $<$ https://antigo.saude.gov.br/images/pdf/2020/marco/04/Instru-----o-Normativa-Calend--rioVacinal-2020.pdf $>$. Acesso em: 9 de março de 2020.

DURANTE, A. L. T. C.; DAL POZ, M. R.. Saúde global e responsabilidade sanitária brasileira: o caso da erradicação da poliomielite. Saúde debate, Rio de Janeiro, v. 38, n. 100, p. 129-138, Mar. 2014 . Disponível em:

$<$ https://www.scielo.br/scielo.php?script=sci arttext\&pid=S0103-11042014000100129 $>$. Acesso em: 04 de março de 2021.

MATO GROSSO. Secretaria de Estado de Saúde. Vacina contra poliomielite será substituída nas unidades de saúde. Cuiabá - MT, 11 de abr. 2016. Disponível em: $<$ http://www.mt.gov.br/-/3849401-vacina-contra-poliomielite-sera-substituida-nas-unidadesde-saude>. Acesso em: 10 de março de 2021.

NETO TAVARES, F. O início do fim da poliomielite: 60 anos do desenvolvimento da vacina. Rev Pan-Amaz Saude, Ananindeua , v. 6, n. 3, p. 09-11, set. 2015 . Disponível em: $<$ http://scielo.iec.gov.br/scielo.php?script=sci arttext\&pid $=\mathrm{S} 2176-$ 62232015000300001>. Acesso em: 25 de fevereiro de 2021.

SILVA, D. S. G.; CÂMARA, C. N. S. Poliomielite no Brasil: histórico e inclusão no mercado de trabalho. EFDeportes.com, Buenos Aires, v. 16, n. 156, maio de 2011. Disponível em: $<$ https://www.efdeportes.com/efd156/poliomielite-no-brasil-historico-einclusao.htm\#: :text=A\%20poliomielite $\% 20 \% \mathrm{C} 3 \% \mathrm{~A} 9 \% 20 \mathrm{uma} \% 20 \mathrm{doen} \% \mathrm{C} 3 \% \mathrm{~A} 7 \mathrm{a} \% 20 \mathrm{infec}$ to $\% 2$ Dcontagiosa $\% 20$ viral $\% 20$ aguda $\% 20$ descrita,foi $\% 20$ descoberta $\% 20$ somente $\% 20 \mathrm{em} \% 20$ 1908>. Acesso em: 23 de fevereiro de 2021. 